\title{
Theotonio Dos Santos, un intelectual revolucionario
}

\author{
Theotonio Dos Santos, a revolutionary intelectual
}

Ivette Lozoya López*

\begin{abstract}
Resumen: Se presenta a continuación una entrevista realizada al sociólogo brasileño Theotonio Dos Santos. La temática tratada principalmente es su paso por Chile a fines de los años sesenta y principio de los setenta. A través de la entrevista se busca indagar en la intelectualidad de la época, los espacios de recepción y difusión de ideas y la vinculación de los intelectuales con los procesos revolucionarios de América Latina y Chile. La entrevista se presenta precedida de una pequeña introducción sobre la biografía de Dos Santos, así también se incluyen una serie de notas a pie de página que contextualiza, aclara o amplía las afirmaciones del entrevistado. De esta manera, las siguientes páginas se pueden leer como un doble texto, el principal con las respuestas del brasileño y uno secundario que va siguiendo la trayectoria del espacio intelectual y político chileno y brasileño.
\end{abstract}

Palabras Clave: Intelectual revolucionario, Unidad Popular, Centro de Estudios Socioeconómicos, Teoría de la Dependencia.

Abstract: Following is presented the interview with the Brazilian sociologist Theotonio Dos Santos. The main issue discussed was his stay in Chile during the sixties and the early seventies. Along the interview there was a look into the intellectuality of the age, the spaces for reception and diffusion of the ideas and the link between intellectuals and revolutionary process in Latin America and Chile. Before the interview there is a biography as introduction to Dos Santos, besides several cross-references are included to contextualize, clarify or amplify the interviewed statements. That way, next pages can be read as a double text, the first one presents the answer of the interviewed and the second one goes along the trajectory of the intellectual and political spaces Chilean and Brazilian.

\footnotetext{
Chilena, Doctora en Estudios Americanos, académica de la Universidad de Santiago de Chile. Ivette.lozoya@usach.cl
} 


\section{Theotonio Dos Santos, intelectual revolucionario}

Theotonio Dos Santos es uno de los intelectuales más brillantes de América Latina. Fue uno de los fundadores de la Teoría de la Dependencia pero también un activista de las luchas sociales latinoamericanas. Comprometido militante, fue fundador de Política Operaria en Brasil (POLOP) y se vinculó al Partido Socialista en Chile colaborando intelectualmente con el proceso revolucionario vivido durante la Unidad Popular. Su compromiso político le costó el exilio dos veces, el primero lo vivió en Chile entre 1968 a 1974 y el segundo en México entre 1974 hasta 1979 cuando regresa a Brasil.

La experiencia en Chile es el principal tema de la presente entrevista, realizada en Río de Janeiro en Junio del 2013 en el marco de la investigación "Pensar la revolución intelectuales y pensamiento latinoamericanos en el MIR chileno 1965-1973”. El objetivo fue reconocer en Theotonio Dos Santos, las características de los que en la investigación en curso habíamos definido como intelectual revolucionario ${ }^{1}$.

La entrevista se articuló en torno a algunas preguntas centrales sobre la condición de intelectual del protagonista pero estuvo plagada de explicaciones contextuales referente a los procesos políticos de Brasil y Chile que nos entregan una rica visión sobre dichos procesos. Para lograr una articulación más clara de las respuestas, hemos sacado las contextualizaciones o explicaciones del proceso hecha por Theotonio Dos Santos y las hemos ubicado al final del texto bajo los subtítulos de "El proceso brasileño" y "el proceso Chileno", tomamos esta decisión en lugar de cortar esos párrafos, debido a que dichas contextualizaciones están llenas de apreciaciones políticas que nos parecieron de total interés porque nos permite conocer a Dos Santos en su doble dimensión, como intelectual y como político.

Las respuestas de Dos Santos nos permiten hacernos un panorama amplio respecto a las discusiones político-académicas que se daban en los años sesenta y principio de los setenta en Chile, así como también, identificar quiénes eran referentes fundamentales y las instituciones desde donde se creaba conocimiento. Para hacer más evidente esta relación, el texto presentado tiene la transcripción de la entrevista a este intelectual brasileño pero también, una ampliación de sus referencias al pie de página de manera que se pueda leer como dos textos que dialogan entre sí.

IL: Durante los años sesenta y los primeros setenta hay una gran cantidad de intelectuales viviendo en Chile, además hay una gran cantidad de instituciones que se desarrollan y acogen a esos intelectuales ¿recuerdas cuáles son y qué importancia tuvieron?

\footnotetext{
${ }^{1}$ Cuando hablamos aquí de intelectual revolucionario, no solo nos estamos refiriendo a un intelectual que adscribía a la revolución, sino a aquel que poniéndose al servicio de las transformaciones profunda es capaz también de revolucionar su campo disciplinario.
} 
TD: Estuvo en Chile casi toda la gente perseguida en América Latina desde el sesenta y cuatro, desde los demócrata cristianos que abrieron bastante el espacio, hasta el golpe. Unos siete u ocho años de una intensidad muy grande, yo llegué en el 66, estuve dos años clandestinos en Brasil, entonces cuando llegué ya había ese ambiente y se fue aumentando con los día.

Los golpes se fueron sucediendo en todas parte, entonces se fue abriendo camino y Chile se fue abriendo como alternativa y después de la victoria de Allende se abrió completamente, ya no tanto de una generación intelectual más madura pero de militantes jóvenes en general. Entre los jóvenes había intelectuales que se fueron abriendo paso y haciendo importante, pero no tanto como los que llegamos en los años sesenta.

La presencia de la intelectualidad fue muy grande sobre todo en este periodo, el 68 fue el año de una rebelión mundial, y después el proceso chileno se fue desarrollando, Chile atrajo a toda una generación, a más de una generación.

\section{IL: ¿y de las instituciones, se acuerda?}

TD: Me acuerdo muy bien de las instituciones. La CEPAL por ejemplo, fue una de las instituciones. Se creó el ILPES a finales del 50 y principio de los 60, era un centro más amplio no solo de economía.

Te llamaría la atención también sobre la creación de FLACSO que es en el 56 o 54, institución de la UNESCO, con al menos dos intelectuales que llegaron independiente de la visión política, uno de ellos era un sociólogo de origen nórdico, que tiene una obra muy grande y una escuela de pensamiento en el entorno de él... y otro que era un francés, que también tenía mucho prestigio. Los dos consiguieron traer para el ambiente latinoamericano la sociología Americana, parte de la francesa y en parte los nórdicos, pero muy fuertemente los norteamericanos principalmente la norteamericana Incorporaron y con una fuerte orientación para las matemáticas la estadística. Fue un pensamiento liberal, fuerte, pero digamos un liberalismo moderado que simpatizó a algunos sectores de la izquierda también pero muy en discusión con la izquierda. Galtung era el sociólogo ${ }^{2}$.

FLACSO formó a toda una generación, nadie que estuviera cercano a la izquierda armada, pero podrían haber apoyado a la Unidad Popular.

\footnotetext{
${ }^{2}$ La institucionalidad académica que se desarrolla en Chile a partir de la instalación de la CEPAL atrajo a una gran cantidad de personalidades intelectuales, uno de ellos fue Johan Galtung, sociólogo, matemático e importante intelectual noruego dedicado a las temáticas de conflicto y violencia. Galtung Vivió en Chile en estos años y fue quien denunció la existencia del proyecto Cámelot con el cual EEUU pretendía intervenir en Chile a través desde la investigación para crear una política antiinsurgente. La denuncia de Galtung (que se enteró por casualidad del plan por un documento erróneo que le hicieron llegar) propició la protesta formal del congreso chileno frente al gobierno norteamericano.
} 
En la Escuela de Filosofía estaba el Departamento Sociología donde Clodomiro Almeyda ${ }^{3}$ ejercía una influencia muy grande, fue el socialista que tuvo relación con los sectores de la izquierda armada. Era un núcleo importante, Eduardo Ruiz ${ }^{4}$ por ejemplo, que después se fue para México, tenía mucho prestigio no volvió a Chile, pero Eduardo era del grupo, muy influyente. El grupo que se forma en los años 60 tiene por lo menos tres instituciones:

Uno era el instituto de Economía de la Facultad de Economía de la [Universidad de] Chile, ahí estuvo gente de bastante peso y que estuvieron en la dirección del gobierno de la Unidad Popular, en la parte económica, uno que estuvo muy próximo fue Martínez ${ }^{5}$. Vúskovic fue el director de la escuela, Vúskovic tenía influencia política e intelectual, bastante $^{6}$. El instituto tenía la ESCOLATINA ${ }^{7}$ que hacia cursos de economía para América Latina y tenía básicamente apoyo de Estados Unidos, con Becas, situación que no era común en esta época. Creo que era la Fundación Ford la que otorgaba las becas, no estoy seguro.

En el caso de FLACSO, las becas eran de Unesco, pero también de los gobiernos porque FLACSO era intergubernamental, pero FLACSO financiaba a los europeos.

La Escuela de Economía tuvo mucha influencia sobre todo en el gobierno de la Unidad Popular desde el ministerio de planificación, nosotros teníamos una muy buena relación con ellos en el $\mathrm{CESO}^{8}$. Eduardo Hamuy era quien lo había creado [Se refiere a la

\footnotetext{
${ }^{3}$ Las instituciones a las que se refiere Dos Santo son aquellas con una fuerte influencia de izquierda, donde la intelectualidad con una explícita definición ideológica ocupaba espacios de investigación y docencia. Clodomiro Almeyda, Abogado, escritor y catedrático, militante del Partido Socialista, fue uno de estos pensadores destacados del socialismo chileno. Ejerció como profesor en la universidad de Chile en la Facultad de medicina veterinaria, y en las la Escuelas de Derecho, Ciencias Políticas y Administrativas, Economía y en la de Sociología. También fue profesor en la Escuela de Periodismo de la U. Católica y en Escolatina (postgrado). De 1967 a 1970 -periodo al que se refiere Theotonio Dos Santos en la entrevistaClodomiro Almeyda fue Director de la Escuela de Sociología de la Universidad de Chile. En: http://www.blest.eu/biblio/almeyda/crono.html

${ }^{4}$ Eduardo Ruiz. Chileno, militante del Partido Socialista, sociólogo, fue Director de la Escuela de Sociología de la Universidad de Chile.

${ }^{5}$ Se refiere a Alberto Martínez, militante del Partido Comunista y colaborador en el área de economía del gobierno de la Unidad Popular.

${ }^{6}$ Pedro Vúskovic, economista chileno, se integra a la CEPAL donde trabaja con Raúl Prebisch. Impartía cátedra en la Universidad de Chile donde en 1968 fue nombrado Director del Instituto de Economía y Planificación de la Facultad de Economía. Realizó también, durante este periodo, clases en otras facultades de la Universidad y en la Universidad de Concepción. Fue Ministro de Economía entre 1970 y 1972, Vicepresidente de CORFO entre 1970 y 1973 Pedro Vuskovic, Inéditos, Santiago, Ediciones Tierra Mía, 2005.

${ }^{7}$ ESCOLATINA era un programa para graduados dependiente de la Facultad de Ciencias Económicas de la Universidad de Chile. Tenía como objetivo la preparación de investigadores en Economía. El prestigioso programa va a ser a la postre un espacio de formación para los jóvenes militantes que, convertidos también en expertos, coparan el estado, convirtiéndose en nuestra actual clase política.

${ }^{8}$ El Centro de Estudios Socioeconómicos (CESO) fue una importante Institución de la Universidad de Chile, creado en 1964 funcionó hasta 1973. En este Centro de Estudios confluyeron una gran cantidad de intelectuales de izquierda nacionales y extranjeros, entre ellos: Theotonio Dos Santos, Marta Harnecker, Tomás Vasconi, entre otros. Editaba periódicamente Los cuadernos del CESO y la revista Sociedad y
} 
fundación del CESO]. Eduardo era un hombre Demócrata Cristiano pero con una visión progresista, era muy amigo de Camilo Torres, colombiano, sociólogo, cura, guerrillero, era una mezcla medio extraña.

Él [Hamuy] jugó un papel importante para desarrollar una línea de investigación principalmente electoral, pero no solo electoral, sino todo tipo de encuestas. Cuando llegué, en el 66 inmediatamente fui a trabajar con él por una orientación de Florestan Fernandes ${ }^{9}$. Yo había terminado la maestría en el 64, pero era muy militante y escribía mucho ya había producido unos libros, entonces Florestán me conocía bien

Ahí en el CESO se fue atrayendo más gente y de cierta forma el proyecto de Hamuy fue perdiendo fuerza y el CESO fue orientándose en la dirección de un pensamiento más económico político y sociológico también pero macro, no micro social como el que tenía, adopta una orientación distinta y se convierte en un centro muy importante y con mucha influencia en la Unidad Popular.

Al mismo tiempo los católicos de izquierda que después formaron Mapu -o ya estaban formando el MAPU- formaron el CEREN, que también era un polo importante de gente que luego salió y algunos quedaron, creo que el secretario actual de la OEA estaba ligado al CEREN era MAPU y estaba ligado al CEREN, bueno era el gran hombre de la izquierda pero se fue adaptando, a las relaciones con el estado y con los gobiernos, eso fue negativo ${ }^{10}$.

Yo creo que los centros principales del pensamiento estaban ahí. Una parte importante de los comunistas se fueron para la Universidad Técnica.

Otro lugar muy interesante, pero que no ha aparecido mucho, era el Centro de Demografía, CELADE. Entre las personas que estaban ahí, había un tipo, un filósofo, se dedicaba mucho a escribir, no tenía mucho contacto. El hecho es que, la presencia de él en Chile no fue muy

desarrollo. A diferencia de la CEPAL o la FLACSO que eran más latinoamericanistas, el CESO puso énfasis en los estudios locales aunque sin perderse del contexto continental. En este centro se desarrollaron las primeras encuestas aplicadas a la coyuntura electoral. Con la llegada de los brasileños, los estudios se volcarán de lo cuantitativo a la economía política indagando en la conformación de clases y la formación económico-social chilena. Ver Ivette Lozoya, Intelectuales y política en el Chile de los años 60 y 70 entrevista con Cristóbal Kay. Buenos Aires, Revista Voces y Memoria, $\mathrm{N}^{\circ}$ 6, 2013.

${ }^{9}$ El ILPES. (Instituto Latinoamericano y del Caribe de Planificación Económica y Social) vinculado a la CEPAL funcionaba en Chile desde 1952 y su misión era formar a través de cursos cortos a los economistas latinoamericanos. Este centro, como otros vinculados a la CEPAL, atrajeron a los intelectuales latinoamericanistas de vanguardia. Ver Ivette Lozoya, Debates y tensiones en el Chile de la Unidad Popular ¿La traición de los intelectuales?, Revista Pacarina del Sur, N 17 Octubre-diciembre 2013.

En el caso de Florestan Fernandes, el sociólogo brasileño es reconocido como el fundador de la sociología moderna en su país y era entonces, catedrático de la Universidad de Sao Paulo, desde donde se opuso al gobierno de Vargas. Fernandes fue además, como la mayoría de su generación, un activo militante y opositor a la dictadura militar iniciada en 1964. Expulsado de la universidad en 1969, se exilia en Toronto Canadá hasta 1974. Ver, Fernandes, Heloísa, Florestas Fernandes, un sociólogo socialista. CLACSO, 2008. http://biblioteca.clacso.edu.ar/clacso/se/20100830102958/02ferna.pdf

${ }^{10}$ Se refiere a José Miguel Insulza. 
conocida, pero él vivió ahí muchos años porque estuvo trabajando en el CELADE y de ahí, trabajó sobre la cuestión tecnológica, publicó luego unos libros en Brasil muy interesante ${ }^{11}$. En fin, era gente de mucho nivel y de mucha influencia en el campo más filosófico. Sobre el CELADE se habla poco.

\section{IL: ¿Y cuáles eran los temas de discusión en la época?}

TD: Yo te quería llamar la atención sobre un asunto muy interesante, que fueron la formación de los seminarios de El Capital, fue un momento muy interesante en el que Chile concentró gentes de varias experiencias de lecturas de El Capital. De un lado estaba el grupo paulista, de Sao Paulo con Fernando Henrique Cardoso, Weffort, el grupo de Sao Paulo en el 60, en el 61 se transformó en un grupo de lectura de El Capital con muchos intelectuales importantes, de ellos los dos más prominente que llegarán a Chile serán Fernando Henrique Cardoso y Francisco Weffort, que después será ministro de cultura ${ }^{12}$.

Cuando yo llegué traje la experiencia del grupo de El Capital que formamos en la Universidad de Brasilia, básicamente, Vania [Bambirra] y Ruy Mauro [Marini] ${ }^{13}$ estábamos en ese grupo, los otros quedaron el Brasil, pero nosotros fuimos los tres que llegamos a Chile, al mismo tiempo, llega Marta Harnecker ${ }^{14}$ que trabajaba El Capital con Althusser.

El Che Guevara, había formado un grupo de estudio de El Capital, con la asesoría de un español ruso, que trabajaba a México como especialidad, él asesoraba el grupo que el Che formó con su viceministro. Como el Che salió de Cuba en el 66, ese grupo vino de vuelta para Chile, los chilenos, y Martínez creo que se llama el viceministro del Che. Bueno, los chilenos de este grupo vienen para Chile y los no chilenos también vinieron para Chile

\footnotetext{
${ }^{11}$ La CELADE es un centro de demografía dependiente de la CEPAL que se instaló en Santiago de Chile en 1957, otras oficinas de la CELADE se instalaron en El Cairo y en Bombay. En general, los centros de demografía fueron muy importantes en la época ya que son estos espacios desde dónde se comenzaron a analizar los problemas sociales asociados al desarrollo, ahí también se comenzó a debatir sobre la marginalidad. Respecto al filósofo, seguramente Dos Santos se refiere a Álvaro Vieria Pinto, brasileño exiliado en Chile, dentro de sus aportes intelectuales están los estudios de una demografía crítica, educación y desarrollo aplicados al contexto latinoamericano.

${ }^{12}$ Respecto a los intelectuales nombrados: Fernando Henrique Cardoso llegó a Chile en 1964 para trabajar en la CEPAL, en este periodo publicará, junto al chileno Enzo Faletto, "Dependencia y desarrollo en América Latina", que se convertirá en un libro clásico. Su estadía en Chile se prolongará hasta 1968, año en que viaja a Francia. Fue fundador de CEBRAP institución clave para la transición brasileña. Francisco Weffort: llega a Chile a trabajar en el ILPES, junto a Fernando Henrique Cardoso de quien sería posteriormente ministro de cultura. Para más detalles respecto a Weffort ver http://www.revistadehistoria.com.br/secao/entrevista/francisco-weffort.

${ }_{13}$ Theotonio Dos Santos, Vania Bambirra y Ruy Mauro Marini, fueron parte del grupo fundador de la Universidad de Brasilia en 1962 cuyo primer rector y líder del proyecto fue Darcy Ribeiro, esta institución fue uno de los polos intelectuales de origen de la teoría de la dependencia.

${ }^{14}$ Una de las intelectuales femeninas de la izquierda más reconocida es Marta Harnecker, entre 1962 y 1968 estudió en Francia bajo la tutoría de Louis Althusser convirtiéndose a su vuelta a Chile, en una de las principales difusoras de la obra del filósofo. Militante socialista desde 1968 se va a integrar al CESO y más tarde, en 1972, va a participar en la fundación del semanario Chile Hoy.
} 
porque no tenían condiciones para volver a sus países en general. Entonces nosotros concentramos derrepente, los principales grupos de lectura de El Capital, porque incluso este hispano ruso del grupo del Che, fue profesor también de dos chilenos muy importantes, uno fue Pepe Valenzuela, José Valenzuela. Valenzuela no formaba parte de nuestro grupo de El capital, pero teníamos una relación muy estrecha y habíamos estado trabajando con él. Entonces la verdad es que hubo una concentración, muy importante de varias direcciones y varias lecturas que se estaban haciendo de El Capital en este movimiento de recuperar el marxismo original. Creo que esto formó parte del desarrollo intelectual de Chile, esta confluencia en torno a un texto tan importante y tan mal leído hasta entonces como era El Capital.

Había un grupo de centroamericanos también, todos con la idea de hacer una lectura sistemática de El Capital y la verdad es que en nuestro instituto, el CESO, continuamos este trabajo, aunque Marta (Harnecker) formó un grupo aparte con la influencia de Althusser que leían atrás, después al frente, no sé... bueno, en realidad si sé, porque la mentalidad de Althusser es muy poco dialéctica, a pesar de haber contribuido para relativizar mucho el análisis marxista, pero él quería poner de un lado la parte teórica y de otro la parte empírica, en lugar de juntar, porque Marx si desarrolla la parte empírica en ciertos momentos de su análisis, la parte empírica ilustraba realmente una base teórica, entonces no es posible poner la teoría primero y luego los ejemplos. Bueno pero Marta trabaja mucho en esa línea y formó mucha gente, hizo varios cursos.

Hubo un momento en víspera de la victoria de Allende, que casi en todas partes se leía El Capital, cosa muy extraña. La gente de arquitectura, leía El Capital, la gente de ingeniería leía El Capital. También hubo un grupo allá arriba con los curas, allá en su seminario, este grupo vino a originar más tarde los Cristianos Por El Socialismo ${ }^{15}$, que era un grupo de cura, básicamente de curas.

\section{IL: ¿Y qué otras discusiones o experiencias de discusión intelectual había? ¿Cómo surge en Chile el estudio de la dependencia?}

TD: Cuando llegué al CESO le plateé a Hamuy inmediatamente la idea de realizar un seminario sobre el concepto de clases, que era un tema que yo había trabajado para la maestría en Brasil, ese seminario duró varias semanas con la participación de mucha gente,

\footnotetext{
${ }^{15}$ La orientación social de los cristianos y de los propios sacerdotes va a tomar distintos rumbos, mientras algunos asumían una postura reformista al alero del crecimiento de la Democracia Cristiana y de las políticas del gobierno de Frei, otros, más influidos por los postulados y el ejemplo de Camilo Torres. Si bien esta última línea era minoritaria, comienza a tomar relevancia política a partir de la Conferencia Episcopal de Medellín en 1968. En 1971 esta corriente en Chile adopta la forma orgánica de Cristianos por el Socialismo y se refuerza cuando en 1972 se realiza en Santiago de Chile el primer encuentro latinoamericano de Cristianos por el Socialismo que contó con la participación del Obispo y 200 sacerdotes y pastores evangélicos Arroyo, Gonzalo (1975) Nota Sobre la Iglesia y Los Cristianos de Izquierda a la Hora del Putsch en Chile. Latin American Perspectives Vol. 2, No. 1, Confronting Theory and Practice (Spring, 1975), pp. 89-99.
} 
Hugo Zemelman ${ }^{16}$, por ejemplo, hizo una intervención sobre el concepto de clases o más bien sobre estamentos y clases de Max Weber. Hugo [Zemelman] era del grupo de Clodomiro [Almeyda].

Entonces ahí empecé a formar un grupo [de jóvenes] que fueron convirtiéndose en auxiliares de curso, hasta que un año después más o menos, en el 67, formé el grupo de la Teoría de la Dependencia. Era un grupo de estudio sobre la dependencia en América Latina. En ese grupo nosotros dividimos el trabajo, en una parte conceptual y teórica de la que yo me encargaba, y por otra parte un balance del desarrollo Latinoamericano con una tipología de la que se encargó Vania, con esto se editó un libro en la editorial Siglo XXI, hubo 6 ediciones ${ }^{17}$.

También había un estudio sobre la relación con la economía mundial, desde el punto de vista de la economía mundial y dependencia, desde el comercio exterior, movimiento de capital y la dependencia. Cómo el desarrollo está condicionado por esa dimensión de la economía mundial. Orlando Caputo y Roberto Pizarro hicieron un estudio excelente, es de lo mejor hasta hoy. Están peleados los dos, hemos intentado mil veces reencontrarlos ${ }^{18}$.

Sergio Ramos, hizo especialmente un balance de Chile, que fue muy influyente. Era principalmente un estudio desde el Partido Comunista, teníamos ciertas divergencias con él, pero en general, estaba dentro de nuestro enfoque. Las diferencias eran más bien de orden táctico. Por ahí entonces el grupo produjo esos trabajos pero había gente que no participaba directamente en el grupo pero produjeron libros después que estaban en la misma línea.

Han trabajado conmigo por ejemplo Álvaro Briones, él escribió cosas interesantes, Cristóbal Kay ${ }^{19}$ que era un gran observador, leía todo y acompañaba todo, muy serio, ellos se juntaron en el CESO. Estos grupos de la teoría de la dependencia, fueron ganando influencia hasta que yo pasé a ser director del Centro, yo no podía serlo antes porque tenía que tener permiso presidencial para que un extranjero dirigiera una institución del Estado, después que ganó Allende, entonces se hizo el proceso para que me nombraran.

\footnotetext{
${ }^{16}$ Hugo Zemelman: Intelectual chileno, Director de la Escuela de Sociología de la Universidad de Chile entre 1967 y 1970, Su formación intelectual fue en la Universidad de Concepción, FLACSO y Holanda. Luego del golpe militar de 1973 en Chile se radicó en México.

${ }^{17}$ El libro al que se refiere es, América Latina: Historia de Medio Siglo - Volumen I - América del Sur. Cidade do México: Ed. Siglo XXI, 1978.

${ }^{18}$ En el CESO funcionaban varios grupos de investigación, los avances se presentaban en un boletín. En el Boletín del CESO n ${ }^{\circ} 1$ de octubre de 1967 aparece la referencia a la investigación que señala Dos Santos. Se presenta como "Investigación sobre las relaciones de dependencia en América Latina". Autores responsables Theotonio Dos Santos y Orlando Caputo; Ayudantes: Sergio Ramos, Roberto Pizarro, José Martínez. Del grupo de investigación y de la división de los temas salieron algunas publicaciones. De Caputo en coautoría con Pizarro, "Imperialismo, Dependencia y Relaciones Económicas Internacionales", publicada por CESO. Publicado por la Universidad Técnica del Estado está "Desarrollismo y Capital extranjero. Las nuevas formas del imperialismo en Chile". Sergio Ramos, por su parte, Publicará por el CESO en 1972 "Chile. ¿una economía de transición?" trabajo con el cual gana el premio Casa de las Américas, en la categoría ensayo.

${ }^{19}$ Cristóbal Kay era uno de los investigadores adscrito al CESO, experto en temas agrarios. Ver Ver Ivette Lozoya, Intelectuales y política en el Chile de los años 60 y 70 entrevista con Cristóbal Kay. Buenos Aires, Revista Voces y Memoria, N $^{\circ}$ 6, 2013.
} 
Pero ahí llegaron algunas figuras muy importantes, a través de Marta que era muy conocida. El otro fue André Gunder Frank que había sido invitado como profesor visitante en la Universidad de Brasilia, cuando yo, Ruy Mauro y Vania trabajábamos allá y nos ligamos mucho a él en esos seminarios que armó sobre pensamiento funcionalestructuralista americano que él conocía mucho porque había sido alumno en la Universidad de Chicago donde estaba el grueso del conservadurismo americano y André era muy crítico de todo eso y leía nuestro trabajo, discutíamos mucho.

\section{IL: ¿el grupo de la Dependencia se había formado en Brasil? ¿André Gunder Frank lo formó?}

TD: Él fue muy importante [Frank], como también lo fue la presencia de CEPAL. Se estableció un curso con CEPAL y entonces dieron cursos para los alumnos de pos grado de la Universidad de Brasilia, nosotros participamos de esos cursos también y tuvimos un acceso más directo a la CEPAL que no teníamos antes ${ }^{20}$. Hubo un momento también que establecimos contacto con FLACSO que hizo un concurso sacando gente en la facultad de ciencias económicas donde yo me formé y tuvimos un curso de sociología y política y se podía tomar con administración también y eso era parte del ambiente de la facultad de economía, recibíamos mucha gente para discutir como Florestan Fernandes y algunos extranjeros también. Teníamos mucho contacto con lo que se estaba produciendo en general.

De ahí salió un grupo para la selección de FLACSO, en el 58-59, ellos seleccionaron a Simón Schwartzman, que es bastante conocido aquí en Brasil, ese grupo fue uno de los mejores grupos de FLACSO en su etapa inicial. Teníamos una postura bien crítica sobre lo que estaba pasando en FLACSO, nosotros hacíamos la crítica al funcional-estructuralismo americano y ellos [en FLACSO] lo estaban estudiando como el gran avance. Todo eso sirvió como fórmula de los procesos que se desarrollaron en las décadas del 80, 90 que [planteaban] una apertura política, que no fuera revolucionaria en contra de las dictaduras que produjo estos fenómenos como el caso chileno y el brasileño también.

Bueno, entonces se desdobló nuestro grupo de la Facultad, muchos quedaron con nosotros dentro de la línea crítica más profunda, otros, se entregaron a la lucha armada, lo que terminó con la muerte de muchos de ellos.

IL: Pero profesor, cómo usted llega exactamente a Chile, por qué a Chile y no a México por ejemplo como Ruy Mauro Marini, había alguna red que lo acogiera?, ¿había posibilidades ciertas de poder ingresar a una institución en Chile?

TD: Mira, mi decisión de asilarme se dio en el 65 cuando yo fui condenado en rebeldía a 15 años por el tribunal de Minas Gerais. Yo tenía otras condenas pero menores, esa condena indicaba una actitud conmigo muy dura y yo estaba en ese momento clandestino,

\footnotetext{
${ }^{20}$ Con Nosotros se refiere a él, Ruy Mauro Marini y Vania Bambirra. El grupo de brasileños había participado en la fundación de la POLOP y junto a André Gunder Frank iniciarán los debates sobre la dependencia latinoamericano, posteriormente, los tres llegarán a Chile y se incorporarán como investigadores en el CESO.
} 
había sido apartado de la universidad en la primera semana del golpe el interventor de la universidad apartó a 4, en un principio éramos 4 pero después continuó y a mediados del 65 éramos 150, ya nadie conseguía quedarse ahí, entonces, con eso yo me sentí en la necesidad de irme. En esos momentos yo estaba como secretario general de la Política Operaria ${ }^{21}$ que era el grupo que nosotros formamos en el 61, pero la verdad es que no tenía poderes de Secretario General, había otro compañero que era Erick Sachs ${ }^{22}$ tenía mucha influencia en la dirección y había en ese momento una situación difícil de definición. Nosotros habíamos terminado un programa socialista para Brasil que fue hecho por la Comisión Política y la Dirección Ejecutiva y yo aparecía como Secretario General, pero la verdad es que había una situación que estaba por explotar. Había mucho descontento en varias parte con la actividad práctica de la Dirección, porque nosotros desde el primer número de la revista y del periódico ${ }^{23}$ estábamos en contra de la idea de los focos y del foquismo, incluso había un par de artículos de crítica al libro del CHE, a pesar que apoyábamos la Revolución Cubana, no apoyábamos las interpretaciones del Che sobre que fue un foco que se extendió por el país. Hay un libro de Vania sobre Cuba, esa era nuestra interpretación ${ }^{24}$.

La situación era muy complicada dentro de la dirección y cuando sale mi condena entonces discuten, ellos discutieron sobre mi situación y diseñaron un sistema de seguridad para mí y me dejaron sin ninguna acción, entonces con ese contexto yo preferí asilarme y Chile fue el que con más facilidad se consiguió, incluso un grupo incluso a través de la acción popular, gente de la clase media alta, empresarios, etc. nos apoyó en contra de la violencia y ellos me dijeron que tenía que ser Chile. De todas maneras yo había estudiado mucho Chile porque había una buena cobertura de acá, había un buen periódico del estado de San pablo, que hizo una buena cobertura, de la elección del 64. Entonces tenía una muy buena opinión muy favorable de Chile, fue por eso que yo vine para Chile. Y bueno estaba la CEPAL y estos centros.

La otra alternativa era México, nosotros habíamos designado a Ruy Mauro para salir por México, él fue preso y salió de la prisión con un proceso aun en curso y las condiciones de vivir legalmente eran muy difíciles y tuvo que entrar en una situación ilegal. Además nosotros necesitamos que él fuera a buscar una relación con Cuba ya que estábamos en ese proceso de articulación con la lucha armada, entonces, la idea de la relación con los cubanos era tener una posición importante ahí. Entonces él llega pero no pudo salir de

\footnotetext{
${ }^{21}$ Política Operaria fue una organización revolucionaria brasileña fundada en 1961, en su fundación estuvieron vinculados varios de los jóvenes intelectuales brasileños de principios de los 60. La organización surgió a partir de la confluencia de varios grupos revolucionarios y se diferenciaba de la izquierda tradicional al reivindicar el carácter socialista de la revolución en Brasil rechazando así la colaboración de clases.

${ }^{22}$ Eric Sachs fue parte de la fundación de Política Operaria y uno de sus referentes destacados como intelectual y dirigente político. Su obra es conocida y difundida internamente en el partido ya que sus documentos escritos circulaban de mano en mano con diversos seudónimos. Ver http://centrovictormeyer.org.br/acervos/arquivo-erico-sachs/

${ }^{23}$ Las revistas de la POLOP era "Política Operaria". Más tarde editarán otras publicaciones como "Marxismo Militante" y "Brasil socialista"

${ }^{24}$ El libro al que se refiere es "La Revolución Cubana, una reinterpretación" editado en Chile en 1967 por PLA.
} 
México, no pudo ir a Cuba y unos meses después yo salí para Chile, Vania salió después para Chile también y después poco a poco se fue realizando la salida de la gente. Bueno esa fue la razón por la que llegué a Chile. No fue una decisión de la organización porque yo rompí con la organización y vine por mi cuenta, Ruy no, él fue [a México] por decisión de la organización, pero después se fue apartando, porque nosotros vimos que el camino del foco estaba dominando la región con efectos muy negativos.

Vania hizo un libro muy importante sobre el balance de 10 años de insurrección en América Latina donde había escritos de gente que estaba en una actitud crítica participando en los levantamientos armados, pero buscando gente que pudiera tener una actitud un poquito más crítica que el repetir las consignas.

Ese libro fue muy bueno porque armó la base para que Vania pudiera levantar la crítica de la tesis foquista. Primero escribió un artículo con el seudónimo de Clear Silva que salió en Master review y terminó con el libro que publicó con su nombre un poco antes del golpe. Llegó a ser publicado en Chile, después Vania consiguió publicar eso en México. La ida a Chile estuvo en ese contexto.

\section{IL: Pascal Allende, en un libro sobre la historia del MIR señala que varios intelectuales, entre ellos usted y Vania Bambirra fueron colaboradores del MIR, ¿usted se sintió en ese Rol?}

TD: ¡Claro! Nosotros estuvimos ahí haciendo conferencias y trabajando con ellos, ellos estaban siempre en mi casa. Yo tenía también muy buena relación con el MR2 y también muy buena relación con las alas del partido comunista y con el Mapu. Pero con el MIR era una simpatía histórica porque era más parecido a Política Operaria y tenían un nivel teórico muy bueno, muy capaz, muy ágil, pero esta cosa de dejarse llevar por eso de los Tupamaros, eso de por aquí es el camino.

Yo me acuerdo de estar un día [en casa] había un escritorio de trabajo y había una sala subiendo la escalera, pero en el escritorio de abajo estaba Vania y yo estaba en una reunión con los dirigentes del MR2 que me estaba contando del asalto que habían hecho de una armería y había sido muy exitoso pero no hicieron mucha publicidad y en ese momento, llegan el grupo del MIR y entran todos armados y entonces Vania los recibe mientras estoy ahí con los otros y yo les digo, te quedas aquí porque si se encuentran va a haber una discusión terrible y yo voy a conversar con Miguel y me fui ahí a conversar con él.

En algunos momentos yo creo que ellos estaban en una cosa muy ostentosa, una cosa infantil, muy juvenil, incluso en un encuentro que tuvieron con la policía, que la policía vio que eran ellos y los tenían para aprehenderlos y ellos sacaron las armas y la policía se fue. Estaban muy felices de todo eso y yo le dije, ahora el MR2 acaba de recuperar una buena cantidad de armas y no están haciendo esa publicidad que ustedes están haciendo, ustedes tienen que moderarse un poco, porque estaban muy entusiasmados con una situación que no permitían que..., pensaban que estaban dando un salto tan grande. 
Eran una fuerza minoritaria, pero que en una buena política de alianzas podía reunir a una fuerza muy grande. Incluso desde fuera de la Unidad Popular.

Y por eso no vimos como malo que el MIR estuviera desde fuera de la Unidad Popular porque era una presión, más si Allende los aceptaba en su grupo de defensa, entonces era una política inteligente, estás afuera pero estás adentro.

\section{IL: Pero intelectualmente, usted cree que influyó en las definiciones políticas del MIR, en las definiciones tácticas.}

TD: El MIR consagra en gran parte la línea de la Unidad Popular excepto en aspectos tácticos, que no están incorporados totalmente en el programa, pero el programa fue muy pensado por nosotros, la idea de que no se trataba de una lucha solamente nacional democrática sino que debía avanzar contra los monopolios y asumir el control directo, directo en la medida que fuera posible de las empresas fundamentales del sistema para poder desde ahí entrar en un proyecto de planificación (planeamiento) general del desarrollo. Los comunistas aceptaron, pero después se vio que no estaban de acuerdo, tenían miedo del efecto que eso provocara, pero tener miedo no es buen expediente político. En los hechos, los trabajadores ocuparon las empresas, no fue por razones estratégicas o ideológicas, ocuparon las empresas porque los patrones se fueron ¿y qué harían entonces? Tienen que ocuparlas, entonces, el proceso avanzó en la dirección que nosotros pensamos casi espontáneamente, entonces claro, el MIR no tenía mucha influencia en los cordones, pero alguna tenía y ahí trabajó mucho en esa dirección. Nosotros queríamos crear y transformar eso en Poder Popular pero no con la perspectiva de tomar el poder sino en llegar a algún tipo de acuerdo con Allende y el proceso político que estaba en marcha para poder actuar junto con el estado, no ser un poder aparte que se enfrentaría a la derecha en toda su dimensión y sobre todo militar. Tenía que ser algo que nos permitiera hacer esa articulación entre el poder nuevo y el poder del estado tradicional y el nuevo avanzado democrático y dirigir parte de ese poder para consagrar incluso, el área social, porque el gobierno tomó las empresas que los empresarios abandonaron, había licitación para eso y las tomó, indicaba un interventor del estado y ese interventor a su vez era obligado a llamar a gente y a instalar una especie de consejo en el cual se basara, entonces la dinámica era así, era una dinámica muy compleja y no era pre fijada, era una influencia como en todo proceso, entonces va asumiendo una forma que el pueblo le da, de acuerdo a su tradición cultural, con su visión del mundo etc. y va organizando su poder de la manera que encuentra.

Entonces, teníamos muy buena relación [con el MIR], pero fue Ruy [Mauro Marini] el que estaba ligado a la Dirección del MIR, yo [era militante] en el Partido Socialista, no estaba en la Dirección, pero tenía relación muy fuerte con la dirección. Era militante del partido, pero considerado como tal hasta cierto punto, porque había mucho que decían que era intelectual, y llegaban y me decían el compañero intelectual, creo que eso era más una restricción, es decir, era militante pero, era intelectual. 
El MIR no era foquista propiamente, si bien tenía influencias de la Revolución Cubana, pero como Vania había escrito esa crítica sobre el foquismo, ellos lo leyeron, lo discutían.

Lo que yo intenté personalmente e intelectualmente, fue tratar de ganar a la izquierda, en conjunto, para transformar los movimientos populares en base de poder. El combate intelectual era muy importante porque los chilenos no son espontaneístas como el resto de Latinoamérica, siempre tuvieron una búsqueda de cálculo político y en eso eran muy buenos en general, todos, el cálculo político, si hago esto voy a conseguir esto por lo tanto yo tengo que cuidar de esto, entonces no se adoptaba una actitud así por tomar, no, todo era calculado, lo que permitía incluso cierto grado de discusión razonable, lo que era importante en un proceso nuevo de la dimensión del chileno tenía que haber ese diálogo y el periódico nuestro, Chile Hoy, fue instrumento de ese diálogo ${ }^{25}$.

Cuando creamos Chile Hoy, Ruy Mauro entró en representación del MIR, no oficialmente, pero teníamos gente del PC, gente del Partido Socialista, dos personas del partido, del MAPU y del MIR. ¿Para qué? Para que la revista fuera una revista de la unidad de la izquierda.

\section{IL: ¿cuál era la diferencia entre la revista Punto Final y Chile Hoy?}

TD: Punto final era la revista de los guerrilleros, del MIR directamente, de los ELENOS también y todos los que estaban por la lucha armada y de los procesos que tomaban esa dirección, entonces Punto final era muy importante porque mostraba documentos de otros lugares donde había que apoyar la lucha armada porque estaban en el proceso, pero no era una reflexión sobre el proceso chileno, ellos fueron por ejemplo los que hicieron la primera divulgación del libro del francés Regis Debray sobre el foquismo.

\section{El proceso de guerra popular en Brasil}

TD: En el 68 hay un golpe dentro del golpe en Brasil se derrota la constitución que los mismos militares habían elaborado en el 67, desde ese momento la represión fue muy dura en contra de los grupos armados. Hay un mito en Brasil que [dice que] en el 64 hay una gran represión, pero es en el 68 cuando la represión adquiere formas mucho más eficientes de tortura que tienen un objetivo muy mediático que es descubrir los grupos armados y en eso son muy eficientes, pero después, continuaron su inercia y continuaron torturando para obtener alguna información, y consiguieron destruir todos los grupos.

En este contexto, la Facultad de Ciencias Económicas tenía un sistema de becas ya de primer año, se desarrollaba un concurso, eran como 4, cuatro para economía y 4 para sociología política y... en total eran 12 becas de personas que ganaban un sueldo mínimo y

\footnotetext{
${ }^{25}$ Chile Hoy fue un semanario publicado en Santiago entre 1972 y 1973, El comité editor estaba compuesto por Jaime Barrios, Theotonio Dos Santos, Pío García, Marta Harnecker, Ruy Mauro Marini, Alberto Martínez y Enrique París. La Directora era Marta Harnecker y los redactores eran: Germán Marín, Jorge Modinguer, Víctor Vaccaro y Faride Zerán.
} 
debían dedicarse a tiempo completo, pero tenían un lugar para trabajar de muy buena calidad y tenían que producir una monografía, esto fue un centro muy fuerte de formación porque permitió la formación de un grupo importante de profesionales. Llegamos a ser 40 o 50, esto fue en la que actualmente se llama Universidad Federal de Minas Gerais, la Facultad de Economía existe aun, pero la Facultad de Economía de hoy no tiene los cursos sociológicos ni políticos, ellos fueron transferidos a la Facultad de Filosofía donde se creó un centro de ciencias Sociales o algo así para donde fue este grupo que vino de vuelta de Chile desde FLACSO, es entonces cuando se crea uno de los 3 o 4 grupos que la fundación Ford creó en Brasil para hacer la transición del restablecimiento democrático en el país.

Pero ocurre que con el golpe de estado y la clandestinidad, se genera una fuerte presión por iniciar la lucha armada. Entonces nosotros comenzamos a negociar con las fuerzas militares [cercanas a la izquierda] y la izquierda que aun existía dentro del gobierno, pero no como opción de poder, el [contacto] más alto que tuvimos ahí -que rompió con las fuerzas armadas en el 68 más o menos- fue Lamarca ${ }^{26}$, el Capitán, ¿por qué? porque las FFAA [golpistas] habían ya expulsado cerca de seis mil oficiales donde estaban sobre todo oficiales nacionalistas y algunos ligados al partido Comunista, entonces quedaban casi militares solamente de derecha, entonces la tendencia normal era pasar a una política $\operatorname{armada}^{27}$.

Iniciamos una relación con Brizola ${ }^{28}$ en Uruguay que en esos momentos era el encargado de hacer la guerrilla por el Che en Brasil, a pesar de que él personalmente al menos no estaba de acuerdo. Él tenía una concepción de tomar el Estado, de revolución, él estuvo dirigiendo un golpe de estado que fracasó, él pretendía salir desde Uruguay para liberar el País. Como se hizo la Revolución del 30, con columnas que salían hacia Río de Janeiro hacia la capital. Nosotros no teníamos una concepción tan bien definida, pero el problema

\footnotetext{
${ }^{26}$ Carlos Lamarca se convertirá en uno de los íconos de aquellos militares de izquierda que abrazaron "la causa del pueblo". Cuando desertó del ejército brasileño en 1968 y se unió a la Vanguardia Popular Revolucionaria, tenía el grado de Capitán. Su vinculación con el pensamiento de izquierda ocurre durante la dictadura y por cercanía con Darcy Rodrigues con quien formará una célula revolucionaria al interior del ejército y se fugará más tarde.

${ }^{27}$ La relación entre las organizaciones de izquierda latinoamericana y las Fuerzas Armadas es uno de los tantos debates sobre la estrategia revolucionaria desarrollados en la época. La posibilidad de ganar a los militares para las filas de la revolución fue en Brasil una posibilidad más cercana que en el resto del continente debido a la influencia de izquierda que había en la institución, el fracaso de esta posibilidad se debió, a que la rama golpista realiza en los primeros años de dictadura, una depuración de sus filas, a esto se suma la lenta reacción de las organizaciones revolucionarias que no aprovechan los contactos que tenían al interior de los cuerpos militares por otro lado, se impone entre los militantes de izquierda revolucionaria la estrategia foquista, desestimando la participación de los militares en la insurrección popular.

${ }^{28}$ Leonel Brizola había desarrollado una importante carrera política en Brasil, fue uno de los fundadores del Partido Trabalhista brasileño y uno de los bastiones de la campaña para que Joao Goulart llegara al gobierno. Con el golpe militar, Brizola intenta organizar la resistencia popular armada y al fracasar debe huir a Uruguay desde dónde guía las acciones armadas. En un libro publicado en 2006 que reúne entrevistas a Manuel Piñeiro, Barba Roja reconoce los vínculos con las guerrillas brasileñas y plantea su admiración por Brizola. Reconoce también la relación entre los postulados del Che y los intentos guerrilleros de Brasil, señala que incluso Marighella mese antes de su muerte, se había abierto a la posibilidad de una guerrilla rural en Brasil.
} 
fue que tuvo que abandonar su concepción para poyar al Che algunos compañeros dicen que la posición de Brizola y otros compañeros que formaron el comando en ese momento estaban inspirados en la idea de muchos Vietnam, es decir, muchas situaciones de insurrección para que Cuba pudiera sobrevivir, entonces frente a argumento de ese tipo, la tendencia fue a aceptar el foco, lo único que conseguimos [fue que ]el foco fuera en una región próxima a un centro urbano, aquí cerca de Río, en Caparao.

Una idea peligrosísima que aquí en Brasil fue un desastre, porque nosotros teníamos un potencial muy grande, partiendo por el movimiento nacional de los sargentos, del ejército, pero sobreestimaron su poder. Teníamos una relación muy especial con ellos [con los sargentos], teníamos el movimiento de marinos que no tenían poder en la estructura de poder de la armada, pero teníamos a los fusileros navales que tenían un dirigente que estaba ligado a nosotros, además Brizola ganó el tercer ejército.

Jango no quiso resistir, pero todo eso estaba ahí, Brizola tuvo que salir [a Uruguay], pero había una articulación, nosotros pudimos estar en un proceso próximo a una insurrección importante.

Yo me había negado a asumir la gestión de la lucha armada, primero porque no estaba convencido de que esta fórmula iba a ser positiva yo creía que debía ser un movimiento más amplio, de masas como fue la revolución cubana, pero la verdad es que la gente fue caminando según lo planteado por Brizola y Brizola atiende a la exigencia del CHE para que formara el foco y terminó preso aquí. Entonces nos dejamos llevar, no tuvimos capacidad de conducir ese proceso armado que terminó siendo un fracaso.

Nosotros teníamos una partida de sargentos y con los marinos, en el 64 después del golpe, hubo una articulación grande con ellos, pero ellos no querían originalmente, no hablaban de foco, no, ellos querían tomar algunos vínculos que ellos tenían en las Fuerzas Armadas y unificarse con la gente del sur, con el general Brizola y hacer una insurrección. En eso estaba Ruy Mauro muy activo. Entonces, la situación era muy complicada dentro de la dirección, y cuando sale mi condena, entonces discuten, ellos discutieron sobre mi situación y diseñaron un sistema de seguridad para mí y me dejaron sin ninguna acción, entonces con ese contex to yo preferí asilarme.

\section{El proceso chileno}

Cuando llegamos a Chile ${ }^{29}$-Ruy estaba en México- ya descubrimos que en Concepción había un grupo de jóvenes muy muy inteligentes, muy activos y con mucha influencia política, en la universidad y en el movimiento de las poblaciones, en el movimiento obrero casi no tenían [influencia], en las poblaciones sí y no solo en el sur, también se desplazan a Santiago y lograron una penetración realmente buena.

\footnotetext{
${ }^{29}$ Se refiere a él y Vania Bambirra
} 
De los grupos armados que había en ese momento estaban los Elenos ${ }^{30}$ del Partido Socialista, yo con ellos tenía buena relación en general, ellos daban apoyos al ELN de Bolivia y había otro grupo que era el MR $2^{31}$ que se aliaron con el Partido Socialista y que al final entraron al Partido Socialista, este era un grupo que tenía una influencia trotskista aunque no eran trotskistas propiamente tal, ahí estaba Álvaro Briones, era un grupo que creía mucho en una insurrección urbana a partir de los cordones industriales.

Habíamos tenido posibilidad de discutir algunas cosas [con el MIR y el MR2], pero lo que ellos no conseguían entender es que estos grupos [de poder local], tenían que de alguna forma -para que el proceso tuviera continuidad- ser reconocidos por el Estado, un poco lo que Chávez hizo en Venezuela, él consiguió reconocer los movimientos, y es una institución ahora los poderes locales.

Parte del proceso chileno respondió a eso y terminó así ganando la idea del poder popular y se creó una legislación, etc. Era unos procesos que se vivía por niveles hasta que realmente [los órganos de poder local] llegaran a tener poder y llegara a afectar la estructura del Estado.

Pero el proyecto estaba, muy abocado al poder dentro de la fábrica, dentro de las empresas. Había movimiento [organización] dentro de las empresas, había movimiento [organización] en las poblaciones pero no llegó a tener una articulación bien definida con la Unidad Popular.

El grupo de los Elenos, por ejemplo, tenían fuerza en esas poblaciones, entonces, la verdad es que teníamos que tener la creatividad suficiente para lograr articular el proceso de masas con el proceso electoral y con la toma de las instituciones democráticas del país. Pero fue muy difícil, Allende se resistió mucho, el Partido Comunista se resistió mucho a pesar de que a nivel de [organización de las] empresas, el Partido Comunista se veía obligado a aceptarlo porque eran la base sindical del partido y se tenía que hacer articular una representaciones ante el empresariado.

\footnotetext{
${ }^{30}$ Bajo el internacionalismo del Che se funda el Ejército de Liberación Nacional en 1967, la sección chilena estará conducida por Elmo Catalán (periodista chileno, militante del Partido Socialista, morirá cuando combatía en la guerrilla de Nancahuasú en Bolivia) Beatriz Allende (La Tati era hija de Salvador Allende. Era médico y recibió instrucción militar en Cuba, se casó con un funcionario de los servicios de inteligencia cubana y se suicidará en Cuba luego del golpe militar en Chile) y Arnoldo Camú (Abogado de profesión, luego de su experiencia en la guerrilla del Che pasa a ser jefe del Aparato Militar del Partido Socialista y participó en la resistencia al golpe de Estado en inmediaciones de la Legua. Fue detenido el 23 de septiembre de 1973 y posteriormente asesinado)

${ }^{31}$ El MR2 o Movimiento Revolucionario Manuel Rodríguez fue una organización revolucionaria chilena que adscribió a la lucha armada. Surgen luego de la expulsión desde el MIR y luego se fusionarán con el Partido Socialista. Ver Mauricio Rojas Casimiro, La división del partido socialista de Chile en la primera etapa de la dictadura (1973-1979), Revista Divergencia, 2013

http://www.revistadivergencia.cl/ediciones/05_enero_julio_2014/01_la_evol_del_ps_chile.php
} 
Vuscovic [desarrolló] una experiencia muy importante, porque intentó crear un consejo de planeamiento compuesto por representantes de empresas sociales ${ }^{32}$, las que el Estado tenía. Ahí había un plan de desarrollo que se discutía con los mismos obreros, esto era una experiencia muy adelantada y muy importante y que generaba resistencia. El poder de las empresas en un momento determinado y los Cordones Industriales se mezclaron y se convirtió en un poder hasta militar. Tenían que defender las empresas, entonces se necesitaba gente, unidades militares de defensa dentro de las empresas organizadas a partir de los cordones industriales

En nuestra revista Chile Hoy, nosotros discutimos todo eso, intentamos ganar a la gente para una concepción más compleja de la revolución, no era la insurrección Rusa, no era la Revolución Cubana - mal interpretada como también la rusa lo fue muchas veces y otras experiencias- era el proceso chileno, y ese proceso tenía esa complejidad, que había que integrar todas estas corrientes que impulsaban la transformación revolucionaria.

Eso no se articuló, si bien hasta el último momento la base estaba organizada, no había un comando que articulase a todos, Allende no quiso, prefirió el suicidio, entre otras cosas porque él confiaba mucho en Pinochet, además como se esperaba un golpe de estado los dirigentes de los grupos militares de cada partido crearon una coordinación para detener el golpe y quien presidía esta coordinación era Pinochet, nombrado por Allende para presidir esta coordinación para detener el golpe, cuando Allende descubre que el golpe está liderado por Pinochet ve que no tiene posibilidades y aun intentó negociar con Pinochet y Pinochet lo llamó muy violentamente y vio finalmente que no tenía una base en que apoyarse.

Allende tenía ciertos límites, él veía el Poder Popular como una duplicidad del poder, él no tenía una apertura para atraer ese poder [popular] hacia adentro del proceso de transición política. La formación de la izquierda Latinoamericana nunca fue muy desde abajo, era más bien de clase media, ella no tiene confianza en los trabajadores, hasta cierto punto no más, pero para lo más decisivo, no.

El Partido Comunista representaba mucho eso también, porque como tenía esa influencia que venía de la Unión Soviética ellos tenían la idea de que las cosas se hacen de arriba hacia abajo, entonces ellos tenían muchas dudas sobre esto. Pero era un momento clave, no había una intervención de grupos izquierdistas, no, el momento era espontáneo y para poder influir en la situación había que despertar, entonces lo que intentaron fue algo que lograra la formalización del movimiento, que permitiría [legitimarlo] desde arriba, eso fue la Ley de Propiedad Social, donde creaban los núcleos por empresa, creaba elecciones en cada empresa y los representantes se articularon de una forma en que los sindicatos tenían mucho poder.

Recibida: 22 Noviembre $2014 \quad$ Aceptada: 3 junio 2015

\footnotetext{
${ }^{32}$ Se refiere al Área de Propiedad Social.
} 


\section{Bibliografía}

Gonzalo Arroyo, Notas sobre la Iglesia y los cristianos de izquierda a la hora del Putsch en Chile. Latin American perspective Vol. 2, N ${ }^{\circ}$, Confronting Theory an Practice pp 89-99, 1975.

Heloísa Fernandes, Florestas Fernandes, un sociólogo socialista. CLACSO, 2008. http://biblioteca.clacso.edu.ar/clacso/se/20100830102958/02ferna.pdf

Ivette Lozoya, Debates tensiones en el Chile de la Unidad Popular ¿la traición de los intelectuales? Pacarina del Sur N| 17 octubre-diciembre, 2013.

Ivette Lozoya Intelectuales y política en el Chile de los 60 y 70: entrevista con Cristóbal Kay. Revista Voces y Memoria, Buenos Aires, 2013.

Mauricio Rojas Casimiro, La división del partido socialista de Chile en la primera etapa de la dictadura (1973-1979), Revista Divergencia, 2013.

http://www.revistadivergencia.cl/ediciones/05_enero_julio_2014/01_la_evol_del_ps_chile. php

Pedro Vuskovic, Inéditos, Santiago, Ediciones Tierra Mia, 2005. 